\title{
TERRITORIAL ANALYSIS OF SEISMIC PERFORMANCE OF ANCIENT CHURCHES: METHODS AND APPLICATION TO CASE STUDIES
}

\author{
D'Amato M. ${ }^{1}$, Laguardia R. ${ }^{2}$, Gigliotti R., ${ }^{2}$ Formisano A. ${ }^{3}$ \\ ${ }^{1}$ DICEM - Dept. of European and Mediterranean Cultures: Architecture, Environment, Cultural Her- \\ itages, University of Basilicata, Via Lanera, 75100 Matera, Italy \\ michele.damato@unibas.it \\ ${ }^{2}$ DISG - Dept. of Structural Engineering, "Sapienza" University of Rome, \\ Via Eudossiana 18, 00184 Rome, Italy \\ e-mail: \{raffaele.laguardia, rosario.gigliotti\}@uniroma1.it \\ ${ }^{3}$ Dept. of Structures for Engineering and Architecture, University of Naples "Federico II", \\ Piazzale Tecchio 80, 80125 Naples, Italy \\ antoform@unina.it
}

\begin{abstract}
In this paper two simplified methods are presented in order to assess the seismic performance of a set of Italian ancient churches. The methods applied are characterized by an increasing refinement level, requiring only some qualitative information in order to evaluate representative indexes of global seismic response. The methods considered may be applied for screening and identifying the current priorities at a territorial level and for planning, where necessary, more refined analysis for evaluating seismic response and required interventions (if necessary). Finally, applications to case studies are illustrated and compared with the aim of highlighting the limitations of the methods considered.
\end{abstract}

Keywords: Ancient masonry churches, cultural heritage, monuments, seismic risk, seismic vulnerability 


\section{INTRODUCTION}

Recent earthquakes have revealed, due to significant damage encountered, high vulnerability of cultural heritage [1]-[2]. Therefore, to date several works have been proposed in the published literature in order to evaluate the actual seismic risk of existing structures, considering different cultural heritage assets, such as palaces, old buildings, churches, monuments, etc. [3]-[7].

Among these works, also fast appraisal methods for preliminary screening the seismic vulnerability at a territorial level have been proposed, too. They have the advantage of requiring, with limited costs, few and not quantitative information for estimating a global index (also indicated as score) useful, in relative terms, for comparing seismic performance of an entire territorial asset. At the end of this preliminary screening, more refined methods have to be applied for specific and more precise evaluations, and also for designing the interventions required [8]-[15].

Recently a multilevel approach is indicated by Italian Directive [16], where three Levels of Valuation (LV) are considered for seismic assessment. These levels, indicated as LV1, LV2 and $L V 3$ have a different refinement level requiring an increasing information amount. Specifically, the first two levels ( $L V 1$ and $L V 2$ ) are established on simplified analyses for seismic assessment, while FEM analyses are possible through the $L V 3$ level. In addition, with particular reference to ancient churches, recently in accordance with the approach indicated by the Italian Directive, also a simplified method has been proposed in $[14,15]$ indicated as Level of Evaluation 0 ( $L V 0)$. This method is very simple to apply and, coherently with the multilevel approach indicated in [16], is simpler to use representing a fast appraisal method useful at a territorial scale as decision-making tool, and applicable with only qualitative and historical information.

This paper deals with a territorial analysis of seismic performance of an ancient churches set located in the historic centre of Matera (Italy), recognized as UNESCO site since 1993. In particular, the main results obtained are illustrated and commented by applying the LV0 method proposed in $[14,15]$, and the LV1 method proposed by the Italian Directive [16]. More details on the churches considered and on the obtained results are reported elsewhere [9, $14]$.

\section{LVO METHOD [14, 15]}

This method, proposed and validated in $[14,15]$, is particularly devoted to territorial seismic analyses of ancient churches. It provides, for each church examined, seismic risk score $R$, by applying the symbolic risk equation $[17,18]$ :

$$
R=H x V \times E
$$

where $H, V$, and $E$ are, respectively, the scores assigned to hazard, vulnerability and exposed elements or assets at risk. The score for each factor is calculated by means of a specific tool, as specified in the following:

Tool 1 allows of rating the exposition $E$, through information gathered from classifications of investigated cultural heritage and any conservation document;

Tool 2 provides a scoring related to the seismic hazard considering many threats with the related hazard maps;

Tool 3 is referred to the seismic vulnerability assessment. It assigns a score starting from the available information provided in the other seismic vulnerability forms and any other historic documents archives. 
This method may be also implemented for assessing the seismic vulnerability provided that, unless the exposition factor $E$, the higher the seismic risk the higher the seismic vulnerability. Therefore, under this assumption the seismic risk score $R$, may be calculated as:

$$
R=[H+1] x V
$$

where the score $R$, in accordance with the simplified method, may be calculated through the scores $H$ and $V$, obtained with the Tool 2 and Tool 3, respectively. Moreover, as proposed in this method the score is added to unity for obtaining the resulting score $R$ greater than one. In the following Tool 2 and Tool 3 are briefly described since applied in this study. More details about the Tool 1 may be found in $[14,15]$.

\section{$2.1 \quad$ Tool 2}

Tool 2 is addressed to provide a score regarding several threats including the seismic action. Threats are divided, according to the occurrence frequency, in "sporadic events" and "continuous processes". The intensity assessment may be conducted by referring to existing documents where events occurred into past are reported. If no information is available, therefore a possible intensity estimation may be done considering also data available within the scientific literature. In the following sporadic and continuous processes considered are listed.

Sporadic events. This group considers:

i. earthquake, expressed through the maximum Mercalli Intensity;

ii. landslide or rock fracture as a consequence of an earthquake.

Continuous processes. The following processes are considered:

iii. rainfall erosion, due to the precipitations amount depending on coastal distance, relative humidity, direction and speed of prevailing winds;

iv. physical stress, to assess the material damage provoked by temperature oscillations as, for instance, particles water icing with a consequent disintegration or cracking of materials;

v. air pollution, associated to traffic of vehicles, airplanes and boats, producing dissolution by acid rainfalls;

vi. the socio-organizational, threat analysing the overload or damage on the monuments for the presence of intensive tourism and possible vandalism;

vii. demographic decline, provoking monuments abandonment and maintenance lack.

The damage score $h_{k, i}$, assigned to the $k$-th threat, is reported in the Table 1 for three different intensities: no hazard, low or gradual, catastrophic.

The resulting seismic hazard score, that is a dimensionless parameter ranging between 0 and 1 , is given by the expression:

$$
\mathrm{H}=\sum_{k=1}^{7} h_{k, i}
$$

Table 1-Seismic hazard scoring [14, 15].

\begin{tabular}{|c|l|c|c|c|}
\hline \multicolumn{2}{|c|}{} & \multicolumn{3}{|c|}{ Severity of damage $\mathbf{h}_{\mathbf{k}, \mathbf{i}}$} \\
\cline { 3 - 5 } \multicolumn{2}{|c|}{} & $\begin{array}{c}\text { Threats } \\
\text { No damage/ } \\
\text { No hazard }\end{array}$ & $\begin{array}{c}\text { Low or } \\
\text { gradual }\end{array}$ & Catastrophic \\
\hline \multirow{2}{*}{$\begin{array}{c}\text { Sporadic } \\
\text { events }\end{array}$} & Seismic action & 0 & 0.20 & 0.40 \\
\cline { 2 - 5 } & Landslide or rock fracture & 0 & 0.15 & 0.25 \\
\hline \multirow{4}{*}{$\begin{array}{c}\text { Continuous } \\
\text { processes }\end{array}$} & Erosion & 0 & 0.05 & 0.10 \\
\cline { 2 - 5 } & Physical stress & 0 & 0.05 & 0.10 \\
\cline { 2 - 5 } & Air pollution & 0 & 0.01 & 0.05 \\
\cline { 2 - 5 } & Socio - organizational & 0 & 0.01 & 0.05 \\
\cline { 2 - 5 } & Demographic decline & 0 & 0.01 & 0.05 \\
\hline
\end{tabular}




\section{$2.2 \quad$ Tool 3}

Tool 3 provides a score related to the seismic vulnerability assessment. In order to provide a fast vulnerability estimation several factors are considered, including:

a) foundation system and building position, in order to consider potential weaknesses or deficiencies of foundations;

b) plan and elevation irregularity, that may increase, as known, the vulnerability of the building against earthquakes;

c) distance between walls, by considering wall slenderness, out of plumb, excessive length in plan between two transversal walls and other potential weaknesses;

d) non-structural elements, by considering potential failures of hanged elements or other accessories;

e) roof configuration, by evaluating the roof deformability, its connection to the walls and the effects of thrusts on the walls;

f) conservation status, by considering eventual existing damages and the global and local conservation situations;

g) fire vulnerability.

Four different vulnerability levels are considered for each parameter that are $A, B, C, D$, where $A$ is assigned in the case of absent (or very low) vulnerability, while level $D$ corresponds to the case of high vulnerability. The resulting vulnerability score $V$, may be calculated as weighted sum of the vulnerability scores assigned to each parameter considered:

$$
\mathrm{V}=\sum_{k=1}^{13} \rho_{k} v_{k, i}
$$
(Table 2).

where $v_{k, i}$ is the vulnerability score of the $k$-th parameter and $\rho_{k}$ the associated weight

Table 2 - Parameters scores and weights for seismic vulnerability evaluation [14, 15].

\begin{tabular}{|c|l|c|c|c|c|c|}
\hline \multicolumn{2}{|c|}{ Parameter } & \multicolumn{3}{|c|}{ Vulnerability $\mathbf{V}_{\mathbf{k}, \mathbf{i}}$} & Weight \\
\cline { 3 - 6 } & $\mathbf{A}$ & $\mathbf{B}$ & $\mathbf{C}$ & $\mathbf{D}$ & $\boldsymbol{\rho}_{\mathbf{k}}$ \\
\hline 1 & Position of the building and foundations & 0 & 1.35 & 6.73 & 12.12 & 0.75 \\
\hline 2 & Floor plan configuration or geometry & 0 & 1.35 & 6.73 & 12.12 & 0.5 \\
\hline 3 & Elevation configuration & 0 & 1.35 & 6.73 & 12.12 & 1.0 \\
\hline 4 & Distance between walls & 0 & 1.35 & 6.73 & 12.12 & 0.25 \\
\hline 5 & Non-structural elements & 0 & 1.35 & 6.73 & 12.12 & 0.25 \\
\hline 6 & Type and organization of the resistant system & 0 & 1.35 & 6.73 & 12.12 & 1.5 \\
\hline 7 & Quality of the resistant system & 0 & 1.35 & 6.73 & 12.12 & 0.25 \\
\hline 8 & Horizontal structures & 0 & 1.35 & 6.73 & 12.12 & 1.0 \\
\hline 9 & Roof configuration & 0 & 1.35 & 6.73 & 12.12 & 1.0 \\
\hline 10 & Conservation status & 0 & 1.35 & 6.73 & 12.12 & 1.0 \\
\hline 11 & Environmental alterations & 0 & 1.35 & 6.73 & 12.12 & 0.25 \\
\hline 12 & Construction system alterations & 0 & 1.35 & 6.73 & 12.12 & 0.25 \\
\hline 13 & Fire Vulnerability & 0 & 1.35 & 6.73 & 12.12 & 0.25 \\
\hline
\end{tabular}

\section{LV1 METHOD [16]}

The Italian Directive [16] proposes a multilevel approach for evaluating the seismic performance of a cultural heritage. As introduced, this approach consists of three different Levels of Evaluation, namely $L V 1, L V 2$ and $L V 3$ having an increasing refinement level.

In particular, this study focuses on the $L V 1$ related to the ancient masonry churches proposed in [16], indicated for preliminary evaluation at a territorial scale. This method is particularly simple to use since only qualitative information gathered with a visual inspection are 
required. The method assigns a vulnerability index $i_{v}$, and then estimates the ground acceleration corresponding to the achievement of a certain limit state. This procedure does not allow of designing any structural intervention.

As for the $i_{v}$, it may be comprised between 0 and 1, and estimated through the expression:

$$
i_{v}=\frac{1}{6} \frac{\sum_{k=1}^{28} \rho_{k}\left(v_{k i}-v_{k p}\right)}{\sum_{k=1}^{28} \rho_{k}}+\frac{1}{2}
$$

In the previous equation $\rho_{k}$ is the $k$-th collapse mechanism weight, equal to: 0 if the mechanism is not present or not active, or else between 0.5 and 1 in the other cases. $v_{k i}$ and $v_{k p}$ are scores assigned to the $k$-th mechanism measuring, according to this method, vulnerability and to any seismic-resistant device, respectively. The weights are equal to 1 for the most important macro-elements regarding the seismic behaviour of a church (such as façade overturning, nave longitudinal transversal response, triumphal arch transversal response, etc.), while secondary mechanisms (such as prothyrum - narthex response, mechanisms of transepts and chapels) may have a weight varying between 0.5 and 1 [16].

Once the vulnerability index $i_{v}$ is calculated, ground acceleration corresponding to achievement of Damage Limit State (DLS) and Life-Safety Limit State (LSLS) may be estimated with the equations reported in the following, established on a statistical basis:

$$
\begin{aligned}
& a_{D L S} S=0.025 \cdot 1.8^{2.75-3.44 i_{v}}[g] \\
& a_{L S L S} S=0.025 \cdot 1.8^{5.1-3.44 i_{v}}[g]
\end{aligned}
$$

\section{APPLICATION TO CASE STUDIES}

\subsection{Description of case studies chosen}

The LVO method [14, 15] and the LV1 method [16] are applied in order to perform a territorial scale evaluation regarding five ancient masonry churches. They fall within the historic centre of Matera (Italy), recognized UNESCO site since 1993. The case studies chosen are illustrated in Figure 1 where, for brevity, only a plan of each church considered is reported. The churches considered in this study are: SS Maria della Bruna, San Giovanni Battista, San Pietro Caveoso, San Rocco, San Francesco d'Assisi. They have in common the fact that they were constructed with the same masonry, composed by calcarenite units of sedimentary rock, improperly named 'tufo' (tuff) due to its apparent similarity to the volcanic rock properly denominated tuff, and lime mortar joints. This rock has the main property of being a very porous rock, very soft and characterized by low-compressive strength. This masonry is present with an extraordinary continuity for realizing walls and vaulted structures, and quite often is present in recurrent dimensions. Usually, mortar joints have a thickness varying from $0.5 \mathrm{~cm}$ up to $1.5 \mathrm{~cm}$, while blocks have the following dimensions: $45-60 \mathrm{~cm}$ length, $25-27 \mathrm{~cm}$ height, 20-25 cm width. All the churches have a one-floor elevation configuration and, in some case, they have also more than one nave; the roof structures are made with vaulted structures in masonry, or with wood elements in the case San Pietro Caveoso and San Francesco d'Assisi. In none of the considered churches interventions are present for reducing seismic vulnerability. A detailed description of the churches considered may be found in $[9,14]$. 
SS Maria della Bruna

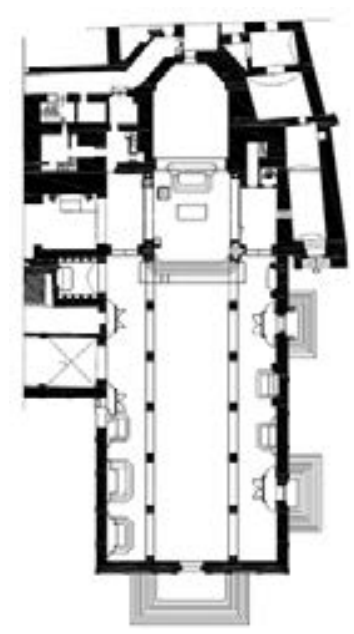

San Rocco

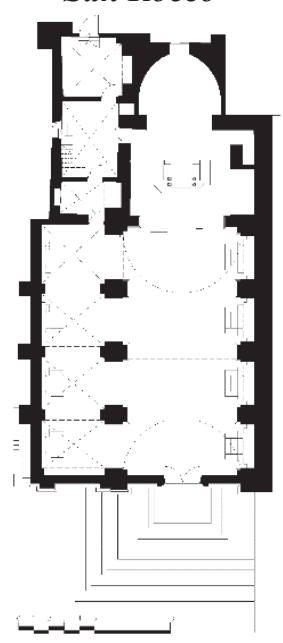

San Giovanni Battista

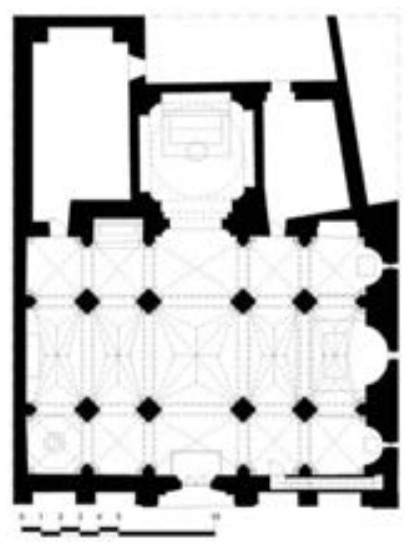

San Francesco d'Assisi

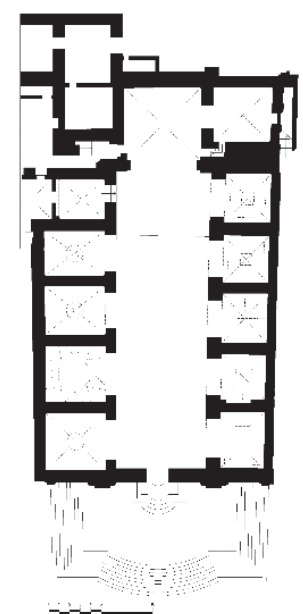

Figure 1 - Floor plan of the considered case studies

\subsection{Application to case studies}

The results of the application of the LVO method are illustrated in the form of histogram in Figure 1. In particular: Figure 1a) reports the hazard assessment according to the Table 1 for obtaining the seismic hazard score H; Figure 1b) illustrates the vulnerability assessment according to the Table 2 for obtaining the vulnerability score $V$; and Figure 1c) summarizes the resulting seismic risk score $R$ calculated with the Eq. (2). As one may one the lowest $\mathrm{R}$ score is obtained in the case of SS Maria della Bruna $(\mathrm{R}=22.15)$, while the highest one is obtained for San Francesco church (i.e. R=30.46). In the case of other churches (San Giovanni Battista, San Pietro Caveoso, San Rocco) similar R scores are found (25.00, 25.25, 25.39, respectively). The results of the seismic risk score reported in ascending order in the Figure 1c) are reported also into Figure 3 , in terms of ratio $R_{i} / R_{\min } . R_{i}$ is the seismic risk score of each church, and $R_{\min }$ is the minimum score found, corresponding in this case to the SS Maria della Bruna score $(\mathrm{R}=22.15)$. The same figure also reports the results of the LV1 method as proposed by the Italian Directive [16]. As for the LV1 method results, the dimensionless return period $T_{i, L S L S} / T_{L S L S \min }$ and the dimensionless ground acceleration capacity $a_{i, L S L S} / a_{L S L S m i n}$ for the Life Safety Limit State (LSLS) are reported. Details on these obtained results are reported in $[9,14]$. Both these ratios express a measure of the seismic vulnerability resulting that the seismic vulnerability decreases as these ratios increase (in terms of acceleration or return period). By 
comparing the results obtained with the $L V O$ and $L V 1$ method, it can be noted that both methods are in good agreement. Therefore, the LVO method may be also used for ranking the seismic vulnerability of a certain sample at a territorial scale. It provides a seismic risk assessment having the same trend of the vulnerability assessment conducted with the LVI method, resulting simpler to use since requires less information than the LVI method.

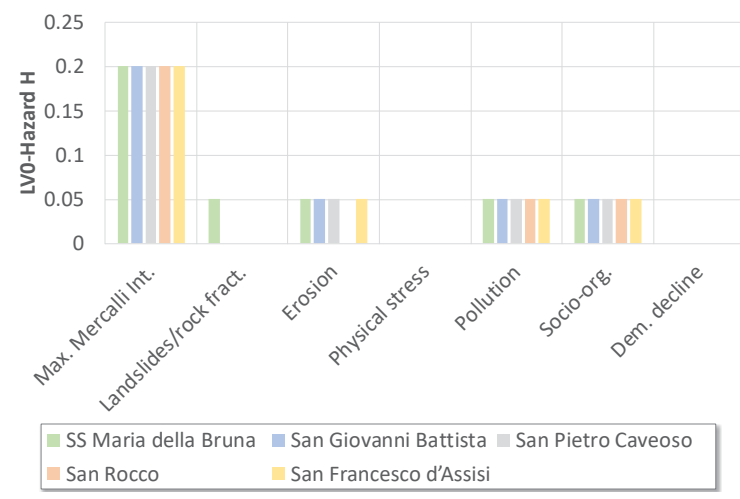

a)

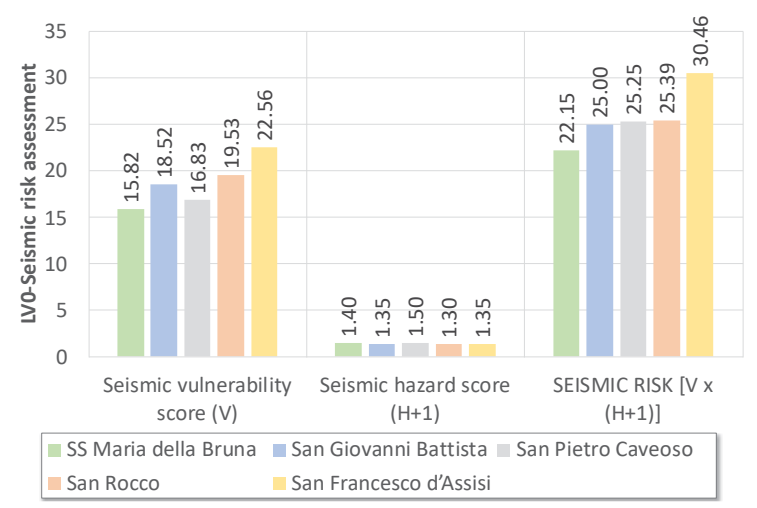

c)

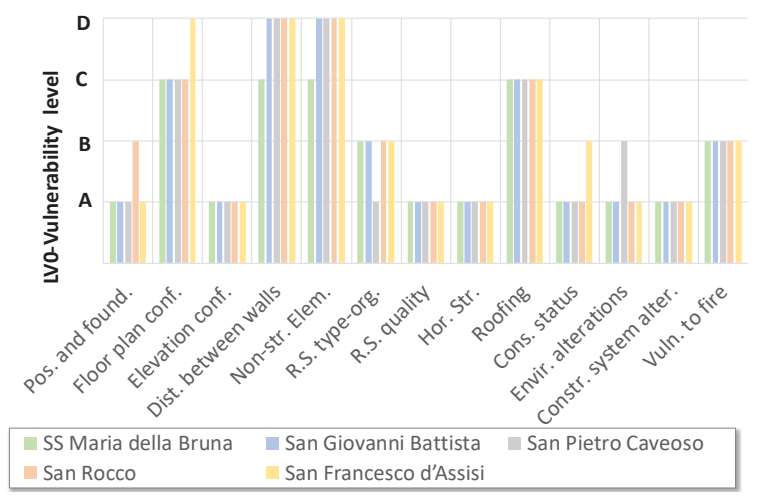

b)

Figure 2 - Results of the LV0 method: a) Hazard assessment, b) vulnerability level assessment and c) resulting seismic risk

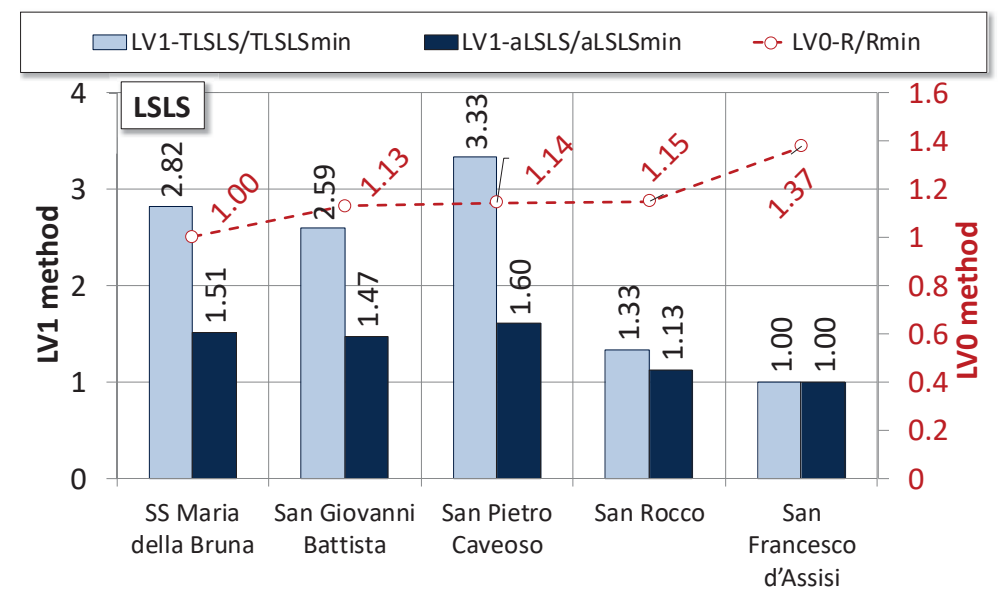

Figure 3 - Comparison of results obtained with the LV0 and LV1 method. 


\section{CONCLUSIONS}

In this paper two simplified methods have been applied in order to assess the seismic performance of a sample of ancient churches. These methods are implemented within a multilevel approach, and result very simple to be applied since they require only qualitative information for obtaining a score to be applied within a territorial evaluation.

As shown, the LVO method is a fast tool for ranking within a certain area the priorities needing to be investigated with more refined methods. While, the LV1 method provides in quantitative terms a first estimation of the seismic performance starting from few qualitative information that may be gathered with an in-situ survey. Both methods, are not capable of designing any intervention. To this aim, within the multi-level approach indicated in the Italian Directive [16], the $L V 2$ and $L V 3$ methods may be applied. However, they require geometrical and mechanical information on structures and materials rarely available and, therefore, known only after specific survey campaigns.

\section{REFERENCES}

[1] D. C. Alexander, Natural disasters. Springer, 2017

[2] B. M. Feilden, J. Jokilehto, Management guidelines for world cultural heritage sites. ICCROM, 1998

[3] D’Amato, M., Laguardia, R., Di Trocchio, G., Coltellacci, M., Gigliotti, R., 2020. Seismic Risk Assessment for Masonry Buildings Typologies from L' Aquila 2009 Earthquake Damage Data. Journal of Earthquake Engineering. https://doi.org/10.1080/13632469.2020.1835750

[4] Laterza, M., D'Amato, M., Casamassima, V.M., 2017. Seismic performance evaluation of multi-span existing masonry arch bridge. AIP Conference Proceedings, 1863, art. no. 450010. International Conference of Numerical Analysis and Applied Mathematics 2016, ICNAAM 2016; Rodos Palace HotelRhodes; Greece; 19 September 2016 through 25 September 2016

[5] D’Amato, M., Laterza, M., Casamassima, V.M., 2017. Seismic performance evaluation of a multi-span existing masonry arch bridge. Open Civil Engineering Journal, 11 (11), pp. 1191-1207

[6] Sarhosis, V., Milani, G., Formisano, A., Fabbrocino, F., 2018. Evaluation of different approaches for the estimation of the seismic vulnerability of masonry towers, Bulletin of Earthquake Engineering, 16 (3), pp. 1511-1545. DOI: 10.1007/s10518-017-0258-8

[7] Krstevska, L., Tashkov, L., Naumovski, N., Florio, G., Formisano, A., Fornaro, A., Landolfo, R., 2010. In-situ experimental testing of four historical buildings damaged during the 2009 L'Aquila earthquake, COST ACTION C26: Urban Habitat Constructions under Catastrophic Events - Proceedings of the Final Conference, pp. 427-432. 
[8] Luchin, G., Ramos, L. F., D’Amato, M., 2020. Sonic Tomography for Masonry Walls Characterization. International Journal of Architectural Heritage, 14(4), 589-604. https://doi.org/10.1080/15583058.2018.1554723

[9] D’Amato, M., Gigliotti, R., Laguardia, R., 2019. Comparative seismic assessment of ancient masonry churches. Frontiers in Built Environment, 5:56. https://doi.org/10.3389/fbuil.2019.00056

[10] Fabbrocino, F., Vaiano, G., Formisano, A., D'Amato, M., 2019. Large-scale seismic vulnerability and risk of masonry churches in seismic-prone areas: two territorial case studies. Frontiers in built environment, 5:102. https://doi.org/10.3389/fbuil.2019.00102

[11] Lopez, S., D’Amato, M., Ramos, L., Laterza, M., Lourenco, P., 2019. Simplifies formulations for estimating the main frequencies of ancient churches. Frontiers Built Enviroment, 5:18. https://doi.org/10.3389/fbuil.2019.00018

[12] Fuentes, D. D., D'Amato, M., Laterza, M., 2019. Seismic Vulnerability and Risk Assessment of Historic Constructions: The Case of Masonry and Adobe Churches in Italy and Chile. SAHC 2018, 11th International Conference on Structural Analysis of Historical Constructions. 18, pp. 1127-1137. Cusco, Perù, 11-13 September 2018: RILEM Bookseries

[13] Ramirez, E., Lourenco, P. B., D'Amato, M., 2019. Seismic assessment of the Matera Cathedral. SAHC 2018, 11th International Conference on Structural Analysis of Historical Constructions (pp. 1346-1354). Cusco, Perù, 11-13 September 2018: RILEM Bookseries

[14] D’Amato, M., Laterza, M., Diaz Fuentes, D., 2020. Simplified Seismic Analyses of Ancient Churches in Matera's Landscape. International Journal of Architectural Heritage, 14(1), 119-138. https://doi.org/10.1080/15583058.2018.1511000

[15] D. Díaz Fuentes, 2016. Diseño de herramientas de evaluación del riesgo para la conservación del patrimonio cultural inmueble. Aplicación en dos casos de estudio del norte andino chileno. México, Escuela Nacional de Conservación, Restauración y Museología

[16] G.U. n. 47. (February 26, 2011). Directive of the Prime Minister dated on 09/02/2011. Assessment and mitigation of seismic risk of cultural heritage with refeence to the technical code for the design of constructions, issued by D. M. 14/ 01/2008 (in Italian)

[17] UNDRO. 1979. Natural disasters vulnerability analysis. New York, NY: United Nations Disaster Relief Organisation

[18] FEMA. 2004. Primer for design professionals (FEMA 389). Washington, D.C: Department of Homeland Security Emergency Preparedness and Response Directorate 